\title{
Bioactivity assessment of endophytic fungi associated with Centella asiatica and Murraya kœngi
}

\author{
Archana Nath, Jyoti Pathak and SR Joshi* \\ Microbiology Laboratory, Department of Biotechnology and Bioinformatics, North Eastern Hill University, Shillong 793022, INDIA
}

\author{
ARTICLE INFO \\ Article history: \\ Received on: 16/09/2014 \\ Revised on: 30/09/2014 \\ Accepted on: 19/10/2014 \\ Available online: $30 / 10 / 2014$ \\ Key words: \\ Centella asiatica; Murraya \\ koengii; Endophytic fungi; \\ Ethanolic extract; \\ Antioxidant; Antimicrobial.
}

\begin{abstract}
The present study attempted to evaluate the antimicrobial and antioxidant activity of fungal endophytes associated with Centella asiatica and Murraya koengii, the ethnomedicinal plants used in traditional practices . Two endophytic fungi Aspergillus oryzae CeR1 and Colletotrichum gloeosporioides MKL1 were isolated from C. asiatica and $M$. koengii respectively which were characterized morphologically and by using rDNA- internal transcribed spacer. The total antioxidant power and free radical scavenging activity of the fungal extracts was estimated using the total phenolic content and 2, 2-diphenyl-1-picrylhydrazyl (DPPH) free radical assay along with the flavonoids and alkaloids content. The DPPH free radical assay showed that the ethanolic extract of endophytic fungi Aspergillus oryzae CeR1 had higher radical scavenging activity than Colletotrichum gloeosporioides MKL1. Antimicrobial activity of fungal extract tested against three bacterial strain namely, Staphylococcus aureus MTCC 96, Streptococcus pyogenes MTCC1925, Enteroccocus faecalis MTCC2729 and one fungal strain Candida albicans MTCC183 showed inhibition of growth of test organisms except Staphylococcus aureus MTCC96.
\end{abstract}

\section{INTRODUCTION}

Endophytic microorganisms are recognized as one of the most chemically promising groups of microorganisms in terms of diversity and pharmaceutical potential. These are microorganisms that grow in the intercellular spaces of higher plants without causing visible damage to their hosts and comprise especially of fungi and bacteria [1]. These microorganisms, in some way contribute to the well being of the plant and being associated with living tissues they are not considered as saprophytes. There are reports indicating the endophytic organisms to be the chemical synthesizers inside the host plants [2]. The biosynthesized chemicals include bioactive compounds used by the host as a defense against pathogens. Some of these bioactive compounds have been proven to be a source for novel drug which are reported to be useful as agro-chemical, antibiotics, immunosuppressant, antimicrobial, anti-parasitic, antioxidant, anticancer agents [3]. The wide spectrum of bioactive secondary metabolites that are characterized from endophytic microbes especially fungi include alkaloids, benzopyranones, flavonoids, phenolic acids, quinines, steroids,

* Corresponding Author

SR Joshi, Department of Biotechnology and Bioinformatics, North-

Eastern Hill University, Shillong-793022, India.

Phone: +913642722405, Fax : +913642550076,

E-mail: srjoshi2006@yahoo.co.in terpenoids, tetralones, xanthones [4]. The ethno-medicinal plants have been recognized as a repository of endophytes with prospects of providing novel metabolites of pharmaceutical importance $[3,5,6]$. Many natural products associated with endophytic fungi have been to be potential as antifungal, anti-oxidant, anticancer, anti-inflammatory and antimicrobial agents [7].

Preliminary survey of Murraya koengii has demonstrated that it has antioxidant, antidiabetic, antibacterial, larvicidal, hypoglycaemic, antiprotozoal, hypolipidemic, antilipid peroxidative, respiratory protective, antihypertensive, cytotoxic and trypsin inhibitor activity [8]. Likewise chemical constituents reported in Centella asiatica include asiaticoside, madecassoide, madecassic acid, asiatic acid, glucose, rhamnose, terpenoids, sitosterol, stigma sterol, fatty oils like glycerides of palmitic acid, stearic acid, linoleic acid, linolenic acid, vitamins like ascorbic acid, and calcium, iron, and phosphate $[9,10]$. C. asiatica has also been reported to be useful in the treatment of inflammations, diarrhea, asthma, tuberculosis and various skin lesions and ailments like leprosy, lupus, psoriasis and keloid [11, 12].

The exploration of plants for endophytic fungi can be of immense value in screening for potential metabolites as was the case with Taxus brevifoia which had fungal endophyte that produced metabolites independently of the tree [13]. The present investigation was designed to characterize the endophytic fungi associated with the two ethnomedicinal plants, Centella asiatica 
and Murraya koengii with the aim to characterize the associated endophytic fungi and investigate their antimicrobial and antioxidant activity. The hypotheses for the study was to assess if the associated endophytic fungi have some properties as already reported for their host plant and if so, the endophytes can be bioprospected as microbial cell factories for metabolites of pharmaceutical importance.

\section{MATERIALS AND METHODS}

\subsection{Sampling}

Mature healthy plant parts ( leaves, roots, shoots/ branches) with no visible symptoms of disease were carefully selected from different regions based on their traditional usage, brought to the laboratory in sterile bags and processed within $24 \mathrm{hr}$ after sampling.

\subsection{Surface sterilization and isolation of the endophytic fungi}

Isolation of endophytic fungi was done according to the method described by Hallmann et al. [14] with minor modifications. The plant samples were rinsed gently in running water to remove adhered dust and debris and were cut into $2 \mathrm{~mm}$ segments which were surface sterilized with $70 \%$ ethyl alcohol for 1 min. The segments were soaked in $4 \%$ sodium hypochlorite solution for $3 \mathrm{~min}$, and then rinsed with $70 \%$ ethyl alcohol for 1 min, rinsed with sterile distilled water and blot dried on sterile filter paper followed by drying under laminar airflow chamber. The segments were then inoculated into potato dextrose agar (PDA, Himedia, India) plates and incubated at $25 \pm 2{ }^{\circ} \mathrm{C}$ for 5-7 days. The growth of endophytic fungi from the plant segments were observed once a day. Hyphal tips growing out of the plated segments were transferred into a fresh PDA plates and incubated at $25 \pm 2^{\circ} \mathrm{C}$ for 5 days to obtain pure cultures. The pure fungal cultures were preserved on the agar slant at $4^{\circ} \mathrm{C}$.

\subsection{Morphological features}

Microscopically, the endophytic fungal isolates were tentatively identified on the basis of their hyphal features, arrangement of spores and reproductive structures.

\subsection{Molecular characterization of endophytic fungi}

Genomic DNA of the fungal endophytes was isolated using the HiPurA fungal DNA isolation kit (Himedia). The DNA samples were stored at $4^{\circ} \mathrm{C}$ for immediate use and stored at $-20^{\circ} \mathrm{C}$ for long-term storage. Fungal rDNA-ITS region was amplified using the fungal domain specific ITS1 and ITS4 [15]. The PCR reaction mixture comprised of $10 \mu$ l fungal DNA, $5 \mu 110 \times$ PCR buffer, $1 \mu \mathrm{l}$ of $10 \mathrm{mM} \mathrm{dNTP}, 0.25 \mu \mathrm{l}$ Taq polymerase, $2 \mu \mathrm{l}$ each of the forward and the reverse primers in a total reaction volume of $50 \mu 1$. PCR was performed in a Gene Amp 9700 Thermal Cycler (Applied Biosystems, USA) with an initial denaturation step at $94^{\circ} \mathrm{C}$ for $5 \mathrm{~min}$, followed by 30 cycles of $94^{\circ} \mathrm{C}$ for $1 \mathrm{~min}, 52^{\circ} \mathrm{C}$ for $30 \mathrm{sec}$, and $72^{\circ} \mathrm{C}$ for $1 \mathrm{~min}$, with a final extension step of $72^{\circ} \mathrm{C}$ for $10 \mathrm{~min}$. The amplified ITS was analysed in $1.5 \%$ agarose gel electrophoresis in $1 \mathrm{X}$ Tris-acetate-EDTA with a marker ladder of 100-bp and ethidium bromide staining. The amplified ITS products were purified using QIA Quick Gel Extraction Kit (Qiagen, Hilden, Germany) according to manufacturer's instructions. Big dye ready reaction dye deoxy terminator cycle sequencing kit (Applied Biosystems) was employed and sequenced in Applied Biosystems 3700 Genetic Analyzer. The obtained sequences were then analyzed using the BLAST algorithm and closely related phylogenetic sequences obtained from the National Centre of Biological Information (NCBI) database. The phylogenetic tree was constructed using Neighbor Joining method in MEGA 5 [16].

\subsection{Preparation of fungal extract}

The cultivation of fungus was done on $100 \mathrm{ml}$ Potato dextrose broth by placing agar blocks of actively growing pure culture ( $3 \mathrm{~mm}$ in diameter) in $250 \mathrm{ml}$ Erlenmeyer flask. Each flask was incubated at $25 \pm 2^{\circ} \mathrm{C}$ for 3 weeks with periodical shaking at $150 \mathrm{rpm}$. The culture was then filtered through three layers of muslin cloth to remove fungal mycelia. The culture filtrate was then filtered thrice with equal volumes of solvent ethanol. The organic phase was collected and the solvent removed by evaporation under reduced pressure at $45^{\circ} \mathrm{C}$ using rotary vacuum evaporator. The dry solid residue was re-dissolved in ethanol $(5 \mathrm{mg} / \mathrm{ml})$ and evaluated for its antimicrobial and antioxidant activities.

\subsection{Test microorganisms}

Staphylococcus aureus MTCC 96, Candida albicans MTCC183, Streptococcus pyogenes MTCC1925, and Enteroccocus faecalis MTCC2729 procured from Institute of Microbial Technology (IMTECH, India) were used as indicator organisms for antimicrobial activity. Test bacteria were subcultured every two weeks on fresh nutrient agar slants and incubated at $37^{\circ} \mathrm{C}$, whereas $C$. albicans was subcultured every four week on fresh PDA slant and incubated at $37^{\circ} \mathrm{C}$. The cultures were kept at $4^{\circ} \mathrm{C}$ until further use.

\subsection{Antimicrobial activity by well-diffusion method}

The antimicrobial activity of the crude extracts of fungi was carried out on Mueller Hinton agar medium for test bacteria and Potato dextrose agar medium for test fungus. Using the sterile cork borer $7 \mathrm{~mm}$ wells were made in which $20 \mu \mathrm{l}$ of crude ethanol fraction was loaded on inoculum swapped plates. The plates were observed for zone of inhibition after incubation for $24 \mathrm{hr}$ at $37^{\circ} \mathrm{C}$ for bacteria and at $25^{\circ} \mathrm{C}$ for fungus.

\subsection{Radical scavenging activity using DPPH method}

Different concentrations of the extracts $(10 \mu \mathrm{l}, 25 \mu \mathrm{l}$, $50 \mu \mathrm{l}, 75 \mu \mathrm{l}$ and $100 \mu \mathrm{l})$ were taken in test tubes and the volume adjusted to $100 \mu \mathrm{l}$ with ethanol. Three $\mathrm{ml}$ of $0.1 \mathrm{mM}$ ethanolic solution of DPPH was added to these tubes. The mixture was shaken vigorously, left to stand for $30 \mathrm{~min}$ in the dark, and the absorbance was measured at $517 \mathrm{~nm}$. The percentage inhibition of 
DPPH radical by the sample extract was calculated using the following relation:

DPPH scavenging effect $(\%)=[(\mathrm{A} 0-\mathrm{A} 1 / \mathrm{A} 0) \times 100]$

Where, $\mathrm{A} 0$ is the absorbance of the control reaction and $\mathrm{A} 1$ is the absorbance in presence of the extract.

\subsection{Estimation of Total Phenolic Content (TPC)}

The total polyphenolic content in the fungal culture extract was determined calorimetrically using the Folin-Ciocalteau (FC) method as described by Singleton et al. [17] with minor modifications. $0.2 \mathrm{ml}$ of test sample was mixed with $0.2 \mathrm{ml}$ of FC reagent and allowed to stand for $10 \mathrm{~min}$ to which $0.6 \mathrm{ml}$ of $20 \%$ sodium carbonate $\left(\mathrm{Na}_{2} \mathrm{CO}_{3}\right)$ was added and mixed thoroughly. The reaction mixture was incubated at $40^{\circ} \mathrm{C}$ for $30 \mathrm{~min}$ and absorbance measured at $765 \mathrm{~nm}$ with gallic acid taken as standard.

\subsection{Phytochemical analysis}

\subsubsection{Flavonoid Tests}

Presence of flavonoids in ethanolic extracts of endophytic fungi was carried out using the method of Brain and Turner [18] and Trease and Evans [19]. Shinoda's test for Flavonoids: About $5 \mathrm{mg}$ of the fungal extract concentrate was dissolved in ethanol to whcih $3 \mathrm{mg}$ magnesium powder was added followed by few drops of concentrated hydrochloric acid $(\mathrm{HCl})$. An orange coloration indicated the presence of Flavonoids. Ferric Chloride test for Flavonoids: About $5 \mathrm{mg}$ of the extract concentrate was dissolved in $2 \mathrm{ml}$ of ethanol to which a few drops of $10 \%$ ferric chloride solution were added. A green-blue coloration indicated the presence of a phenolic hydroxyl groups.

Sodium Hydroxide $(\mathrm{NaOH})$ test for Flavonoids: The fungal extract was warmed and filtered, and $200 \mu \mathrm{l}$ of $10 \%$ aqueous $\mathrm{NaOH}$ was added to the filtrate. This produced a yellow coloration. A change in color from yellow to colorless on addition of dilute $\mathrm{HCl}$ was an indication of $\mathrm{r}$ the presence of flavonoids.

\subsection{2 .Alkaloid Test}

Wagner's test: About $5 \mathrm{mg}$ of the fungal extract was treated with Wagner's Test reagent $[1.27 \mathrm{~g}$ of Iodine and $2 \mathrm{~g}$ of Potassium iodide in $100 \mathrm{ml}$ of distilled water]. A reddish brown color indicated the presence of alkaloid [20].

\section{RESULTS}

\subsection{Isolation and identification of fungi}

A total of nine and seven isolates from Centella asiatica and Murraya Koenigii respectively were isolated from different parts of the plants. Based on microscopic and morphological features, one isolate each from the plants (CeR1 from $C$. asiatica and MKL1 from $M$. koengii) were considered for molecular characterization and phytochemical study. The rDNA-ITS region was amplified, sequenced and submitted to the NCBI GenBank with accession numbers KF358716 and KF358717. BLAST search of ITS gene sequences affiliated the endophytic fungal isolates CeR1 and MKL1 to be closest homolog of Aspergillus oryzae and Colletotrichum gloeosporioides respectively (Fig.1,2).

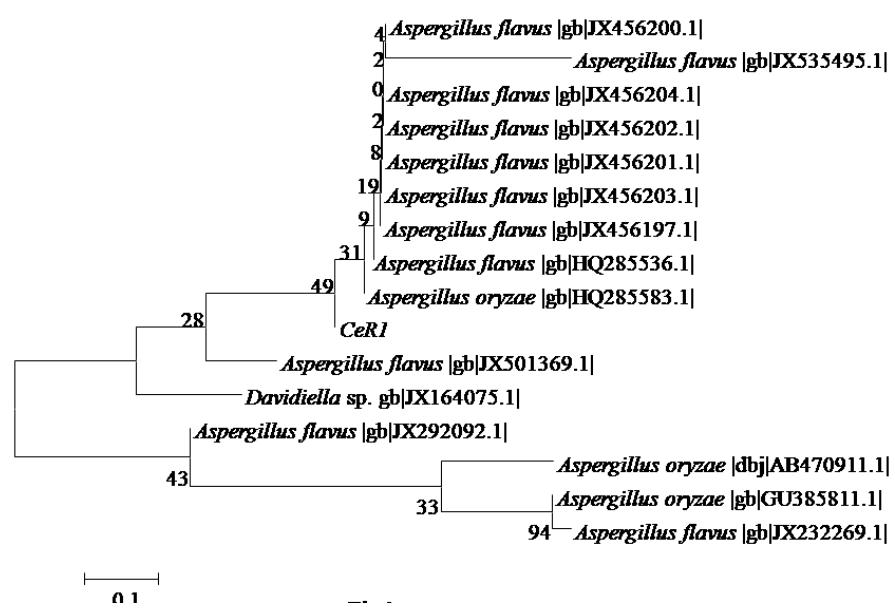

Fig. 1: Evolutionary positions of the endophytic fungal isolate CeR1 with other related fungal species based on internal transcribed spacer sequence similarity.

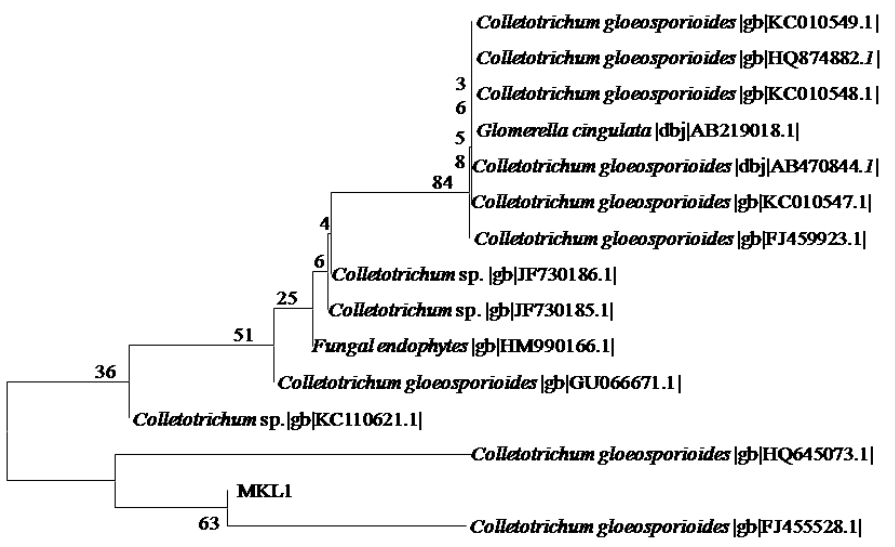

0.5

Fig. 2: Evolutionary positions of the endophytic fungal isolate MKL1 with other related fungal species based on internal transcribed spacer sequence similarity.

\subsection{Antimicrobial assay}

The crude extracts of the fungi displayed considerable antimicrobial activity against some pathogens (Table 1). None of the fungal extracts exhibited inhibition of Staphylococcus aureus MTCC 96. The crude extract of Aspergillus oryzae CeR1 inhibited the growth of Candida albicans MTCC183 but had no effect on Streptococcus pyogenes MTCC1925 and Enteroccocus faecalis MTCC2729. In contrast, the crude extract of Colletotrichum gloeosporioides MKL1 had no effect on Candida albicans MTCC183 and Staphylococcus aureus MTCC96.

\subsection{DPPH radical scavenging activity}

The comparative analysis of DPPH assay between Aspergillus oryzae $\mathrm{CeR} 1$ and Colletotrichum gloeosporioides MKL1 revealed the latter to have higher radical scavenging activity than the former (Table 2). The fungal extracts showed better activity than ascorbic acid which was used as the reference standard. 
Table. 1: Antimicrobial activity as zone of inhibition (in $\mathrm{mm}$ ) of endophytic extracts by well diffusion method.

\begin{tabular}{|c|c|c|c|c|c|}
\hline $\begin{array}{c}\text { Plant parts used } \\
\text { for isolation }\end{array}$ & $\begin{array}{c}\text { Characterized } \\
\text { isolates }\end{array}$ & $\begin{array}{c}\text { Staphylococcus } \\
\text { aureus }\end{array}$ & Candida albicans & $\begin{array}{c}\text { Streptococcus } \\
\text { pyogenes }\end{array}$ & Enteroccocus faecalis \\
\hline Roots & Aspergillus oryzae (CeR1) & - & + & - & - \\
\hline Leaf & Colletotrichum gloeosporioides (MKL1) & - & - & ++ & + \\
\hline
\end{tabular}

-No zone of inhibition; + inhibition zone between 10 14 mm; ++ inhibition zone between 15 20 mm.

Table. 2: Scavenging activity $(\%)$ on DPPH radicals of ethanolic extracts of endophytic fungi at different concentration ( $\mu \mathrm{g} / \mathrm{mL})$.

\begin{tabular}{|c|c|c|c|c|c|}
\hline \multirow{2}{*}{ Fungal Isolates } & \multicolumn{5}{|c|}{ Concentrations $(\mu \mathrm{g} / \mathrm{ml})$} \\
\hline & 10 & 25 & 50 & 75 & 100 \\
\hline$\overline{\text { Aspergillus oryzae (CeR1) }}$ & $4.66 \pm 0.05$ & $26.16 \pm 0.13$ & $15.29 \pm 0.08$ & $104.88 \pm 0.10$ & $72.88 \pm 0.18$ \\
\hline Colletotrichum gloeosporioides (MKL1) & $0.67 \pm 0.05$ & $47.89 \pm 0.06$ & $73.84 \pm 0.08$ & $60.09 \pm 0.08$ & $52.77 \pm 0.06$ \\
\hline Ascorbic acid & $0.15 \pm 0.21$ & $16.05 \pm 0.3$ & $17.75 \pm 0.25$ & $19.56 \pm 0.19$ & $21.36 \pm 0.43$ \\
\hline
\end{tabular}

Table. 3: Total phenolic content (TPC) in the ethanolic extracts of endophytic fungi.

\begin{tabular}{ll}
\hline Fungal isolates & TPC (mg gallic acid equivalent / g dry wt.) \\
\hline Aspergillus oryzae (CeR1) & $1.4 \pm 0.01$ \\
Colletotrichum gloeosporioides (MKL1) & $0.72 \pm 0.03$ \\
\hline
\end{tabular}

Table. 4: Test results for flavonoids and alkaloids from the endophytic fungi.

\begin{tabular}{|c|c|c|c|c|c|}
\hline \multirow{2}{*}{ Fungal isolates } & \multicolumn{3}{|c|}{ Flavonoids } & & \multirow{2}{*}{ Alkaloids } \\
\hline & Shinoda's Test & Ferric chloride Test & Sodium hydroxide Test & & \\
\hline $\begin{array}{l}\text { Aspergillus oryzae }(\mathrm{CeR} 1) \\
\text { Colletotrichum gloeosporioides (MKL1) }\end{array}$ & - & - & - & - & + \\
\hline
\end{tabular}

\subsection{Total phenolic content (TPC)}

Total phenolic content was found to be higher in the culture extract of Aspergillus oryzae $\mathrm{CeR} 1$ as compared to Colletotrichum gloeosporioides MKL1 (Table 3) when expressed as gallic acid equivalent (GAE) i.e. mg gallic acid/g dry wt. The levels of phenolic contents in the endophytic fungal extracts were significantly different from each other.

\subsection{Phytochemical analysis}

Presence of flavonoid and alkaloid was noted in the extracts of Colletotrichum gloeosporioides MKL1 whereas both were absent in the crude fungal extract of Aspergillus oryzae CeR1 (Table 4).

\section{DISCUSSION}

There has been a growing interest in finding the alternative to reduction of the problem of drug resistance among the pathogens and antimicrobial metabolites from fungal endophytes has been explored as one of the alternate approaches [5]. The fungal isolates obtained from both the medicinal plants in the present study i.e. Aspergillus oryzae CeR1 and Colletotrichum gloeosporioides MKL1 revealed activities and phytochemical contents which can be explored for generation of bioactive metabolites. The endophytic fungus, Colletotrichum gloeosporioides MKL1 showed better inhibition of growth of the pathogenic microorganisms when compared to Aspergillus oryzae CeR1. This could be due to their higher efficiency in metabolite production indicating that these fungi have differing activity potential. There is a vast diversity of microbes which still remains untapped for evaluation of metabolites production that may possess valuable bioactivities including antioxidant activity [21]. There is a strong relationship between total phenol content, flavanoid, alkaloid and antioxidant activity, as phenols possess strong scavenging ability for free radicals due to their hydroxyl groups [22]. Therefore, the phenolic content of may directly contribute to their antioxidant action as has been reported for plants $[23,24,25]$. Phenolic compounds are powerful chain breaking antioxidants and are reported to be associated with antioxidant activity and play a crucial role in stabilizing lipid peroxidation [26]. The observation in the study revealed that crude ethanolic extract of Aspergillus oryzae CeR1 does not show the presence of both alkaloid and flavanoid, however, it showed highest phenolic content which makes it a potential antioxidant. The DPPH assay has been largely used as a quick, reliable and reproducible parameter to search the in vitro general antioxidant activity of pure compounds [27].

The effect of antioxidants on DPPH is thought to be due to their hydrogen donating ability [28, 29]. A freshly prepared DPPH solution exhibits a deep purple color which disappears when an antioxidant is present in the medium. An antioxidant molecules can quench DPPH free radicals and convert them to a colorless product, resulting the decrease in absorbance. The reducing capacity of compounds thus, serve as indicator of potential antioxidant property [30]. Considering the total phenolics, reducing power and the DPPH radical scavenging activity as indices of antioxidant activity of the extract, the present findings reveal the potential of the extract as a source for natural antioxidants [31]. It indicates that the metabolites of endophytic fungi isolated from Aspergillus oryzae CeR1 and Colletotrichum gloeosporioides MKL1 could be potential agents in scavenging free radicals and treating diseases related to free radical reactions.

A moderate correlation exists between the amount of total phenolics and the biological activity, when a comparison of both antioxidant and antimicrobial activities is made in relation to the amount of total phenolics of different natural extracts $[32,33$, 
$34,35,36]$ In this context, the crude extracts of the endophytes, Aspergillus oryzae CeR1 and Colletotrichum gloeosporioides MKL1 presented a moderate antioxidant activity and a better greater antimicrobial activity opening scope for their exploration as a natural antioxidant in food industries and other pharmaceutical preparations $[37,38]$. This work is the first report on fungal endophytes of Centella asiatica and Murraya koenigii which provides an insight into understanding some basis of therapeutic properties traditional medicine. However, further studies on the characterization of the metabolites from the culture extracts of endophytic fungi obtained in the study as well as their in vivo assays are necessary for their pharmaceutical bioprospection.

\section{ACKNOWLEDGEMENT}

The support received as research grant from the Department of Biotechnology, Govt. of India is thankfully acknowledged.

\section{REFERENCES}

1. Petrini O. Fungal endophytes of tree leaves. In: Andrews JH, Hirano SS (Ed) Microbial Ecology of the Leaves. Springer- Verlag, New York. 1991; 179-197 pp.

2. Owen NL, Hundley N. Biodiversity of Marine derived fungi and identification of their metabolites. Sci. Prog. 2004; 87:79-99.

3. Gunatilaka AAL. Natural products from plant associated microorganisms: Distribution, Structural diversity, bioactivity and implications of their occurrence. J. Nat. Prod. 2006; 69: 509-526.

4. Tan RX, Zou WX. Endophytes: A rich source of functional Metabolites. Nat. Prod. Rep. 2001; 18:448-459.

5. Strobel G, Daisy B, Castillo U, Harper J. Natural products from endophytic microorganisms. J. Nat. Prod. 2004; 67:257-268.

6. Wiyakrutta S, Sriubolmas N, Panphut W, Thongon N, Danwiserkanjana K, Ruangrungsi N, Meevootisom V. Endophytic fungi with antimicrobial, anti-cancer, anti-malarial activities isolated from Thai medicinal plants. World J. Microb. Biotech. 2004; 20:265272.

7. Verma VC, Kharwar RN, Strobel GA. Chemical and functional diversity of natural products from plant associated endophytic fungi. Nat. Prod. Commun. 2009; 4:1511-32.

8. Ajay S, Rahul S, Sumit G, Paras M, Mishra A, Gaurav A . Comprehensive review: Murraya koengii linn. Asian J. Pharm. Life Sci. 2011; 1:2231-4423.

9. Sastri BN. The Wealth of India: A Dictionary of Indian Raw Materials and Industrial Products, Council of Scientific and Industrial Research, New Delhi. 1956; 4: 101-103.

10. Trease GE, Evans WC. Textbook of Pharmacognosy. The Williams \& Wilkins Company, Baltimore 2, Maryland. 1966; 15:130, 303, 480.

11. Ullah MO, Sultana S, Haque A, Tasnim S. Antimicrobial, cytotoxic and antioxidant activity of Centella asiatica. Eur. J. Sci. Res. 2009; 30:260-264.

12. Zheng CJ, Qin LP. Chemical components of Centella asiatica and their bioactivities. Chin. J. Integr. Med. 2007; 5:348-351.

13. Stierle A, Strobel G, Stierle D. Taxol and taxane production by Taxomyces andreanae, an endophytic fungus of Pacific yew. Sci. 1993; 260:214-6.

14. Hallmann J, Berg G, Schulz B. Isolation procedures for endophytic microorganisms. Springer Brelin Heidelberg, New York. 2007.

15. White TJ, Bruns T, Lee S, Taylor JW. Amplification and direct sequencing of fungal ribosomal RNA genes for phylogenetics. In: Innis MA, Gelfand DH, Sninsky JJ, White TJ (Ed). PCR protocols: A guide to methods and applications. Academic Press, New York. 1990; 315-22 pp.

16. Tamura K, Peterson D, Peterson N, Stecher G, Nei M, Kumar S. MEGA5: molecular evolutionary genetics analysis using maximum likelihood, evolutionary distance, and maximum parsimony methods. Mol. Biol. Evol. 2011; 28:2732-2739.

17. Singleton VL, Orthofer R, Lamuela-Raventós RM. Analysis of total phenols and other oxidation substrates and antioxidants by means of Folin-Ciocalteu reagent. Methods Enzymol. 1999; 299:152-78.

18. Brain KR, Turner TD. The practical evaluation of phytochemicals. Wright Science Technical, Bristol. 1975; 56-64 pp.

19. Trease GE, Evans WC. Pharmacognosy. Saunders Publishers, London. 2000; 15:42-44, 221-229, 246-249, 304-306, 331-332, 391393.

20. N. Raaman. Phytochemical Techniques. New India Publishing Agency, New Delhi. 2006.

21. Motta AS, Cladera-Olivera F, Brandelli A. Screening for antimicrobial activity among bacteria isolated from the Amazon basin. Braz. J. Microbiol. 2004; 35:307-10.

22. Rosalind T, Dutta BK, Paul SB. Evaluation of in vitro antioxidant activity, estimation of total phenolic and flavonoid content of leaf extract of Eurya japonica Thunb. Asian J. Pharm. Clin. Res. 2004 6:152-155.

23. Wojdylo A, Oszmianski J, Czemerys R. Antioxidant activity and phenolic compounds in 32 Selected Herbs. Food Chem. 2007; 105:940-949.

24. Bendini A, Cerretani L, Pizzolante L, Gallina-Toschi T, Guzzo F, Ceoldo S, Marconi AM, Andreetta F, Levi M. Phenol content related to antioxidant and antimicrobial activity of Passiflora spp. extracts. Euro Food. Res. Technol. 2006; 223(1):102-109.

25. Dlugosz A, Lembas-Bogaczyk J, Lamer-Zaraw-ska E. Antoxid Increases Ferric Reducing Antioxidant Power (FRAP) even Stronger than Vitamin C. Acta Pol. Pharm. 2006; 63:446-448.

26. Sharma SK, Gupta VK. In vitro antioxidant studies of Ficus racemosa Linn. root. Pharmacogn. Mag. 2004; 4: 70-74.

27. Koleva II, van Beek TA, Linssen JP, de Groot A, Evstatieva LN Screening of plant extracts for antioxidant activity: a comparative study on three testing methods. Phytochem. Anal. 2002; 13:8-17.

28. Biswas M, Haldar PK, Ghosh AK. Antioxidant and free-radicalscavenging effects of fruits of Dregea volubilis. J. Nat. Sci. Biol. Med. 2010; 1: 29-34.

29. Meir S, Kanner J, Akiri B, Philosoph-Hadas S. Determination and involvement of aqueous reducing compounds in oxidative defense system of various senescing leaves. J. Agr. Food Chem. 1995; 43:1813-9

30. Gherraf N, Ladjel G, labed B, Hameurlaine S. Evaluation of antioxidant potential of various extracts of Traganum nudatum Del. Plant Sci. Feed. 2011; 1: $155-159$.

31. Nath A, Raghunatha P, Joshi SR. Diversity and biological activities of endophytic fungi of Emblica officinalis, an ethnomedicinal plant of India. Mycobiol. 2012; 40: 8-13.

32. Ohwadaa J, Tsukazakia M, Hayasea T, Oikawaa N, Isshikia $\mathrm{Y}$, Fukudaa H, Mizuguchia E, Sakaitania M, Shiratoria Y, Yamazakib T, Ichiharac S, Umedaa I, Shimmaa N. Design, synthesis and antifungal activity of a novel water soluble prodrug of antifungal triazole. Bioorg. Med. Chem. Lett. 2003; 13:191-6.

33. Bhagobaty RK, Joshi SR. Metabolite profiling of endophytic fungal isolates of five ethno-pharmacologically important plants of Meghalaya, India. J. Metabolom. Syst. Biol. 2011;2: 20-31.

34. Bhagobaty RK, Joshi SR. Multi-loci molecular characterisation of endophytic fungi isolated from five medicinal plants of Meghalaya, India. Mycobiol. 2011; 39: 71-78.

35. Bhagobaty R K, Joshi SR. Enzymatic activity of fungi endophytic on five medicinal plant species of the pristine sacred forests of Meghalaya, India. Biotechnol. Bioprocess Eng. 2012; 1: 33-40.

36. Bhagobaty RK, Joshi SR, Kumar R. Penicillium verruculosum RS7PF: a root fungal endophyte associated with an ethno-medicinal plant of the indigenous tribes of eastern India. Afr. J. Microbiol. Res. 2010; 4: 766-770. 
37. Devi LS, Bareh DA, Joshi SR. Studies on biosynthesis of antimicrobial silver nanoparticles using endophytic fungi isolated from the ethno-medicinal plant Gloriosa superba L. Proc. Natl. Acad. Sci., India, Sect. B, Biol. Sci. 2013; DOI 10.1007/s40011-0130185-7.

38. Nath A, Chattopadhyay A, Joshi SR. Biological activity of endophytic fungi of Rouwolfia serpentina Benth, an ethnomedicinal plant used in folk medicines in Northeast India. Proc. Natl. Acad. Sci., India, Sect. B, Biol. Sci. 2013; DOI 10. 1007/s40011-013-01848.

How to cite this article:

Archana Nath, Jyoti Pathak and SR Joshi. Bioactivity assessment of endophytic fungi associated with Centella asiatica and Murraya koengii. J App Biol Biotech. 2014; 2 (05): 006-

011. 